\title{
Factors contributing to the recognition of anxiety and depression in general practice

Henny Sinnema ${ }^{1 *}$ (D), Berend Terluin², Daniëlle Volker ${ }^{1}$, Michel Wensing ${ }^{3}$ and Anton van Balkom ${ }^{4}$

\begin{abstract}
Background: Adequate recognition of anxiety and depression by general practitioners (GPS) can be improved. Research on factors that are associated with recognition is limited and shows mixed results. The aim of this study was to explore which patient and GP characteristics are associated with recognition of anxiety and depression.

Methods: We performed a secondary analysis on data from 444 patients who were recruited for a randomized trial. Recognition of anxiety and depression was defined in terms of information in the medical records, in patients who screened positive on the extended Kessler 10 (EK-10). A total of 10 patient and GP characteristics, measured at baseline, were tested and included in a multilevel regression model to examine their impact on recognition.

Results: Patients who reported a perceived need for psychological care (OR $=2.54,95 \% \mathrm{Cl} 1.60-4.03)$ and those with higher 4DSQ distress scores (OR $=1.03 ; 95 \% \mathrm{Cl} 1.00-1.07)$ were more likely to be recognized. In addition, patients' anxiety or depression was less likely to be recognized when GPs were less confident in their abilities to identify depression ( $\mathrm{OR}=0.97 ; 95 \% \mathrm{Cl} 0.95-0.99)$. Patients' age, chronic medical condition, somatisation, severity of anxiety and depression, and functional status were not associated with the recognition of anxiety and depression.

Conclusions: There is room for improvement of the recognition of anxiety and depression. Quality improvement activities that focus on increasing GPs' confidence in the ability to identify symptoms of distress, anxiety and depression, as part of care according to guidelines, may improve recognition.
\end{abstract}

Keywords: Anxiety, Depression, Recognition, Primary care, General practitioner

\section{Background}

Anxiety and depression are highly prevalent, negatively impact everyday functioning, cause great suffering, and incur high healthcare costs and costs associated with reduced productivity [1-3]. Although clinical guidelines are available $[4,5]$, the management of these disorders in general practice is often suboptimal. Under-recognition of anxiety and depression has been reported, although more severe symptoms may be more easily recognized $[6,7]$. Adequate recognition, diagnosis and treatment of anxiety and depression may decrease the burden of disease [8]. With approximately $75 \%$ of adult patients visiting their general practitioner (GP) at least once a year in the Netherlands, the GP is in a good position to detect anxiety and depression [9]. In the Netherlands more than $75 \%$ of patients diagnosed with psychological problems are

\footnotetext{
* Correspondence: hsinnema@trimbos.nl

${ }^{1}$ Netherlands Institute of Mental Health and Addiction, Trimbos Institute,

Postbox 725, 3500, AS, Utrecht, The Netherlands

Full list of author information is available at the end of the article
}

treated in general practice [10]. Studies showed a wide range of recognition rates of depression and anxiety in primary care, also depending on the method of case ascertainment and the time allowed for GPs to recognize [11-13]. Recognition rates were higher when patient medical record extraction was used over an extended period compared to cross-sectional methods. In addition, when a less specific definition of recognition was used, recognition rates were higher. However, this may also result in more false positives [14].

Characteristics of both GPs and patients influence recognition of anxiety and depression. Many patients do not acknowledge that they suffer from anxiety or depression, and may present themselves in general practice with somatic symptoms [15-18]. Both patients and GPs may prioritise physical problems if they coexist with a (hidden) depression [19]. Even when a psychiatric diagnosis is made the patient or GP may not perceive a need

(c) The Author(s). 2018 Open Access This article is distributed under the terms of the Creative Commons Attribution 4.0 International License (http://creativecommons.org/licenses/by/4.0/), which permits unrestricted use, distribution, and reproduction in any medium, provided you give appropriate credit to the original author(s) and the source, provide a link to the Creative Commons license, and indicate if changes were made. The Creative Commons Public Domain Dedication waiver (http://creativecommons.org/publicdomain/zero/1.0/) applies to the data made available in this article, unless otherwise stated. 
for treatment [20]. Furthermore, some GPs find it difficult to distinguish between 'normal' distress and depression requiring treatment [21]. In the presence of chronic physical health problems GPs and patients tend to normalise distress [22]. In addition, there are barriers related to the access of care (e.g. stigma, lack of information about mental health and available services) [23].

Adequate recognition, and subsequent treatment, could improve outcomes for patients. Previous studies have examined different patient and GP characteristics as possible factors associated with the recognition of depression and anxiety, showing mixed results. Factors associated with recognition include female gender, advanced age, being single, severe depression, comorbid anxiety or depression, chronic somatic co-morbidity, history of depression, having disclosed mental health problems to the GP, and positive attitudes toward help seeking [7, 14, 24-29]. A few studies also examined whether primary care physician characteristics, such as years of experience, education, special interest, knowledge and skills, were associated with recognition of depression [7, 24] and anxiety [14]. Wittchen et al. (2001) found that physicians with more than 5 years of practice experience were more likely to recognize patients with a depression. Janssen et al. (2012) and Piek et al. (2012) concluded that there were no GP characteristics associated with recognition [7, 14]. Furthermore, GPs' attitudes likely constitute an important factor affecting the recognition of anxiety and depression [30-32].

Previous studies showed mixed results regarding factors associated with recognition and other factors are rarely studied. The factors include: (i) patient characteristics: age, married or living together, chronic medical condition, the perceived need for care, psychological symptoms and functional status, and (ii) GP characteristics: attitudes toward the management of anxiety and depression. The aim of the current study was to examine whether these factors are associated with the recognition of anxiety and depression in general practice.

\section{Methods}

\section{Study design}

This study is a secondary analysis of data from a cluster randomized controlled trial of tailored interventions, to improve the management of anxiety and depression in primary care (NTR1912) [33]. The aim of the trial was to determine the clinical and cost effectiveness of tailored interventions to improve compliance with guidelines for the recognition of anxiety and depression in general practice [34-37]. The trial compared training and feedback for GPs with training and feedback supplemented with a tailored intervention. Results showed that the tailored intervention resulted in increased recognition of anxiety and depression (42\% versus $31 \%$; OR =
1.60; 95\% CI:1.01-2.53) [38].The identification of barriers to implementation of guidelines, the development of interventions targeting these barriers, and the application and perceived usefulness of the resulting tailored interventions have been described elsewhere [39]. The sample size was based on the primary trial objectives. The trial was approved by the medical ethics committee of the Institutions for Mental Health (METiGG; Utrecht, the Netherlands) in 2009.

\section{Study population}

The study population included 46 GPs in 23 general practices (12 practices were randomised to the intervention condition and 11 practices to the control condition), and all patients aged 18 years or older visiting one of the participating GPs between September 2010 and June 2011. A total of 7410 patients received an information letter and an invitation to participate and were asked to complete the extended Kessler 10 (EK-10), a validated screening tool for anxiety and depressive disorder in primary care [40]. The screening was returned by 1687 patients (response rate 23\%) and 766 of them (45\%) screened positive and were contacted by telephone. Based on predefined exclusion criteria 158 (21\%) patients were excluded. Exclusion criteria were suicidal ideation and behavior, dementia or other severe cognitive disorders, psychotic disorder, bipolar disorder, dependence on alcohol or drugs, severe unstable somatic condition, insufficient knowledge of the Dutch language, GP diagnosis of anxiety or depression or psychological treatment in the six months before the start of the study. Of the remaining 608 patients, 164 (27\%) patients did not provide informed consent. Therefore, 444 patients screening positive for anxiety and depression were included in the present study. GPs were blind to which patients had entered the study. For further details on recruitment and selection we refer to the study protocol [33].

\section{Measures}

\section{Outcome measure}

The outcome in the present study was GPs' recognition of anxiety or depression, as evidenced by information that was available in the patients' medical records, in the time period from 6 months before to 6 months after the EK-10 screening. Information that was deemed to be indicative of recognition was the presence of terms describing: (i) psychological complaints: anxiety, depression, worrying, sorrow or grief, stress, feeling down, disordered sleeping and unexplained somatic symptoms; (ii) International Classification of Primary Care-1 (ICPC-1) diagnostic codes [41] for anxiety, depression and related psychological problems i.e. acute stress, feeling anger or irritation, behaving irritably or 
angrily, neurasthenia, or (iii) Four-Dimensional Symptom Questionnaire (4DSQ) scores. The 4DSQ can be used to help recognize anxiety and depressive disorders. This self-report instrument can be used to distinguish between stress-related syndromes (termed 'stress', 'burnout' and 'nervous breakdown') and psychiatric disorders (i.e. anxiety and depressive disorders) [42]. Recognition was operationalised this way because diagnostic coding alone strongly underestimates the accuracy of the GP $[14,43]$. The medical records were retrospectively searched by two researchers. They assessed 50 medical records independently and weighted kappa statistics were calculated. The kappa yielded an inter-rater agreement of 96\% (weighted kappa $=0.91$; 95\% CI: 0.79-1.00).

\section{Patient and GP related factors}

The independent variables investigated included patient and GP characteristics that might be associated with the recognition of anxiety and depression. The data were collected at baseline.

Patient characteristics were age, married or living together, presence of a chronic medical condition, psychological symptoms, perceived need for psychological care and functional status. Chronic medical condition was measured with the Dutch Central Bureau of Statistics (CBS) list, a questionnaire containing 28 conditions [44]. Psychological symptoms were measured with the Four-Dimensional Symptom Questionnaire (4DSQ). The 4DSQ has four subscales relating to common psychopathology: distress, depression, anxiety and somatisation; high scores correspond to high symptom levels. Perceived need for psychological care (henceforth "need for care") was measured with two questions after the 4DSQ: "Do you receive any help for these complaints" and "Do you need help to solve these complaints", answered with yes/no. Functional status was measured using the World Health Organisation's Disability Assessment Scale II (WHODAS II) which covers functional impairments in six domains over the past thirty days. The standardised total score, based on 32 items corrected for missing values was calculated $[45,46]$. The domains are communication and understanding, getting around, self-care, getting along with people, life activities and participation in society. Scores range from 0 to 100; high scores indicate functional impairment.

GP characteristics were attitudes to anxiety and depression, measured with the Depression Attitude Questionnaire (DAQ) [47, 48] and with the REASON questionnaire [49]. The DAQ measures GPs' interest in and attitudes toward depressive disorders; respondents are asked to indicate the degree to which they agree or disagree (a 7-point Likert scale in which the discrete anchor points were converted to a 0-100 scale, where 0 means strongly disagree and 100 strongly agree) with 20 statements based on their day-to-day clinical experience. The DAQ consists of 4 components: treatment attitude (high scores indicate a preference for antidepressant drugs, low scores for psychotherapy); professional unease (high scores indicate discomfort in dealing with depressed patients, perception that treating depression is unrewarding and that patients would be better off being managed by a specialist); depression malleability (high scores indicate pessimism about one's ability to modify the course of depression) and depression identification (high scores indicate difficulty in differentiating depression from unhappiness, believes that it originates from recent misfortunes, and that there is likely to be little additional benefit beyond a GP's own treatment. The REASON measures GPs' attitudes to their role in the management of patients with depressive and anxiety disorders (scores can range from 1 to 7), and comprises two subscales: (i) professional comfort with and competence in care of mental health disorders (low scores indicate comfort and competence) and (ii) GPs' concerns about problems with the health care system for management of anxiety and depression (low scores indicate concerns about difficulties).

\section{Statistical methods}

Multiple imputation was used, creating 5 complete datasets to deal with missing values. The imputation model included recognition, condition (intervention or control), patient characteristics (gender, age, born in the Netherlands, married or living together, in paid employment, level of education, 4DSQ score, WHODAS II score, chronic medical condition, need for care, living conditions), and GP characteristics (attitude towards anxiety and depression). Missing values for recognition $(n=24)$, born in the Netherlands $(n=8)$, married or living together $(n=5)$, level of education $(n=4)$, living conditions $(n=3)$, 4DSQ score (4DSQ Distress $n=11$, 4DSQ Depression $\mathrm{n}=11$, 4DSQ Anxiety $n=12$, 4DSQ Somatization $n=30)$, WHODAS II score $(n=17)$, need for care $(n=34)$ were imputed.

The prediction of recognition was examined using multilevel logistic regression analyses. Logistic regression was used because of the binary character of the outcome variable (recognition yes/no). Multilevel analysis was used to account for the clustered design (i.e., patients were clustered within GPs and GPs were clustered within practices), which threatens the mutual independence of the observations [50]. Not taking into account the clustered nature of the data, results in under-estimation of standard errors and over-estimation of statistical significance. The analyses were performed using the Generalized Linear Mixed Models method as implemented in the Statistical Package for the Social Sciences (SPSS) 22 program. All analyses were conducted 
in the 5 imputed datasets and results were pooled using Rubin's rules [51]. We considered 15 potential predictors of recognition, ensuring not to exceed the limit of $10 \%$ of the number of events (i.e. recognition, $n=160$ ) in the sample [52]. First, potential predictors (patients and GP characteristics) were tested through trivariate analyses using recognition as dependent (outcome) variable and condition as effect modifier. The reason to take the trial intervention (condition) into account as a possible effect modifier was that the intervention might have affected the effect of certain predictors on recognition. Predictors and interaction terms with $p$-values $<0.20$ were selected for inclusion in a multivariate logistic regression model. Then stepwise backward selection was used to remove non-significant $(p>0.05)$ predictors and interaction terms one-by one from the model, starting with predictors and interaction terms with the highest $\mathrm{p}$-value. To assess the extent to which the predictors and interactions retained in the final model actually explained the variance in recognition, a receiver operating characteristic (ROC) analysis was conducted using the model-predicted probabilities as test variable and recognition as the outcome variable. The area under the ROC curve (AUC) ranges from 0.5 and 1.0 with larger values indicating more variance explained [53].

\section{Results}

\section{Characteristics of the study population}

Baseline characteristics for patients and GPs are given in Table 1 . The mean age of the 444 patients was 54 years, and $69 \%$ were female. The mean age of the 46 GPs was 49 years, and $54 \%$ were men.

\section{The association of patient and GP characteristics with recognition}

GPs recognized anxiety or depression in 160 patients (36\%). Recognition rates were especially higher in patients who: were younger than 55 years, had a 4 DSQ Distress score of $\geq 11$, had a perceived need for psychological care, and a WHODAS II score of $\geq 21$ (see Additional File 1). Table 2 shows the results of the trivariate and multivariate analyses. Ten predictors and/or their interaction terms with condition had $p$-values < 0.20 in the trivariate analyses and were entered in a multivariate model (in Table 2 indicated by a "₹" sign after the p-value). After the backward selection procedure only 4 predictors and one interaction term remained in the final model. Patients with higher 4DSQ distress scores $(\mathrm{OR}=1.03$; $95 \%$ CI $1.00-1.07)$ were significantly more likely to be recognized. Note that the OR of 1.03 is related to 1 point difference in the Distress score (range $0-32$ ). To illustrate, if a person with 10 points on the Distress scale has a probability of $30 \%$ of being recognized, a person scoring 25 points has a probability of
Table 1 Baseline characteristics of primary care participants $\left(n=444^{*}\right)$ and general practitioners $(n=46)$. Values are numbers (percentages) unless stated otherwise

\begin{tabular}{|c|c|}
\hline \multicolumn{2}{|l|}{ Patient characteristics } \\
\hline Mean (SD) age (years) & $54.3(15.8)$ \\
\hline Married or living together $(n=439)$ & $\begin{array}{l}294 \\
(67.0 \%)\end{array}$ \\
\hline $\begin{array}{l}\text { Number of chronic medical conditions }{ }^{\mathrm{a}} \text { (range: } 0-28 \text {, } \\
\text { mean (SD) }\end{array}$ & $3(2.1)$ \\
\hline 4DSQ ${ }^{\mathrm{b}}$ Distress score (range: $\left.0-32\right)$, mean $(\mathrm{SD})(n=433)$ & $12.2(7.6)$ \\
\hline 4DSQ Depression score (range: $0-12)$, mean (SD) $(n=433)$ & $1.7(2.7)$ \\
\hline 4DSQ Anxiety score (range: $0-24)$, mean $(S D)(n=432)$ & $3.0(3.7)$ \\
\hline $\begin{array}{l}\text { 4DSQ Somatisation score (range: } 0-32) \text {, mean (SD) }(n= \\
414)\end{array}$ & $8.4(5.9)$ \\
\hline Functional status ${ }^{c}(n=427)$ & $23.9(15.7)$ \\
\hline Need for care $(n=410)$ & $201(49 \%)$ \\
\hline \multicolumn{2}{|l|}{ General Practitioner characteristics } \\
\hline \multicolumn{2}{|l|}{$\mathrm{DAQ}^{\mathrm{d}}$ mean score (SD) } \\
\hline Treatment attitudes (range 0-100) & $44.3(7.2)$ \\
\hline Professional unease (range 0-100) & $44.9(7.8)$ \\
\hline Depression malleability (range $0-100$ ) & $40.1(11.0)$ \\
\hline Depression identification (range 0-100) & $46.6(11.1)$ \\
\hline \multicolumn{2}{|l|}{ REASON $^{e}$ mean score (SD) } \\
\hline $\begin{array}{l}\text { Professional comfort with and competence in care of } \\
\text { mental health problems (range 1-7) }\end{array}$ & $3.2(0.4)$ \\
\hline $\begin{array}{l}\text { GPs' concerns about problems with the health care } \\
\text { system for treatment of anxiety and depression (range } \\
1-7 \text { ) }\end{array}$ & $4.4(0.8)$ \\
\hline \multicolumn{2}{|c|}{$\begin{array}{l}{ }^{*} \mathrm{n}=444 \text { unless stated otherwise } \\
{ }^{a} \text { Chronic medical condition was measured with the Dutch Central Bureau of } \\
\text { Statistics (CBS) list } \\
\text { b } 4 D S Q \text { = Four-Dimensional Symptom Questionnaire } \\
\text { 'Functional status was measured with the WHODAS-II = World Health } \\
\text { Organisation's Disability Assessment Scale II (excluding work) } \\
{ }^{d} \text { DAQ: Depression Attitude Questionnaire } \\
\text { e REASON questionnaire: GPs' attitudes to their role in the management of } \\
\text { anxiety and depressive disorders }\end{array}$} \\
\hline
\end{tabular}
anxiety and depressive disorders

$40 \%$. Also patients who had reported a need for care $(\mathrm{OR}=2.54,95 \%$ CI $1.60-4.03)$ were significantly more likely to be recognized. In addition, patients' anxiety or depression was less likely to be recognized when GPs had less confidence in their abilities to identify depression (DAQ subscale depression identification; $\mathrm{OR}=0.97$; 95\% CI 0.95-0.99). Married or living together was the only predictor showing an interaction with condition, suggesting that being married or living together was a predictor of recognition only in the intervention condition but not in the control condition. Actually, recognition was lowered in patients who were married or living together in the intervention condition $(\mathrm{OR}=0.39$; $95 \%$ CI 0.16-0.95). The ROC analysis showed an AUC of 0.698 (95\% CI 0.645-0.751) suggesting that the amount of variance in recognition explained by the joint predictors in the final model was "poor" to "fair" [53]. Patients' 
Table 2 Results of the trivariate and multivariate multilevel logistic regression analyses predicting recognition of anxiety and depression

\begin{tabular}{|c|c|c|c|c|c|c|c|}
\hline \multirow[t]{2}{*}{ Independent variables (predictors) } & \multicolumn{4}{|c|}{ Trivariate analysis } & \multicolumn{3}{|c|}{ Multivariate analysis } \\
\hline & $\overline{O R}$ & $95 \% \mathrm{Cl}$ & $P$ & & OR & $95 \% \mathrm{Cl}$ & $P$ \\
\hline Condition (intervention/control) & 1.50 & $0.94-2.39$ & 0.087 & $\neq$ & 3.08 & $1.47-6.46$ & 0.003 \\
\hline Age & 0.98 & $0.96-1.00$ & 0.060 & $\neq$ & & & \\
\hline Condition ${ }^{\mathrm{a}}$ Age & 1.00 & $0.97-1.03$ & 0.989 & & & & \\
\hline Married or living together (ref. not married or living together) & 1.40 & $0.77-2.52$ & 0.268 & $\neq$ & 1.25 & $0.67-2.35$ & 0.478 \\
\hline Condition ${ }^{\mathrm{a}}$ Married or living together & 0.33 & $0.14-0.79$ & 0.013 & $\neq$ & 0.39 & $0.16-0.95$ & 0.039 \\
\hline Number of chronic medical conditions ${ }^{a}$ & 0.94 & $0.83-1.08$ & 0.389 & & & & \\
\hline Condition ${ }^{\mathrm{a}}$ Number of chronic medical conditions & 1.03 & $0.85-1.25$ & 0.784 & & & & \\
\hline \multicolumn{8}{|l|}{$4 \mathrm{DSQ}^{\mathrm{b}}$} \\
\hline Distress & 1.03 & $0.99-1.07$ & 0.098 & $\neq$ & 1.03 & $1.00-1.07$ & 0.024 \\
\hline Condition ${ }^{\mathrm{a}}$ Distress & 1.04 & $0.99-1.10$ & 0.153 & $\neq$ & & & \\
\hline Depression & 1.04 & $0.95-1.15$ & 0.393 & & & & \\
\hline Condition ${ }^{\mathrm{a}}$ Depression & 1.03 & $0.89-1.16$ & 0.666 & & & & \\
\hline Anxiety & 1.02 & $0.94-1.10$ & 0.615 & & & & \\
\hline Condition ${ }^{\mathrm{a}}$ Anxiety & 1.04 & $0.93-1.15$ & 0.512 & & & & \\
\hline Somatization & 1.01 & $0.96-1.06$ & 0.736 & & & & \\
\hline Condition ${ }^{\mathrm{a}}$ Somatization & 1.04 & $0.97-1.11$ & 0.301 & & & & \\
\hline Need for care (ref. no need for care) & 2.77 & $1.56-4.91$ & 0.001 & $\neq$ & 2.54 & $1.60-4.03$ & 0.000 \\
\hline Condition ${ }^{\mathrm{a}}$ Need for care & 1.18 & $0.49-2.85$ & 0.719 & & & & \\
\hline \multicolumn{8}{|l|}{$\mathrm{DAQ}^{\mathrm{C}}$} \\
\hline Treatment Attitudes & 1.02 & $0.97-1.06$ & 0.508 & & & & \\
\hline Condition ${ }^{a}$ Treatment Attitudes & 0.96 & $0.88-1.04$ & 0.294 & & & & \\
\hline Professional Unease & 0.98 & $0.94-1.02$ & 0.322 & $\neq$ & & & \\
\hline Condition ${ }^{\mathrm{a}}$ Professional Unease & 1.05 & $0.99-1.11$ & 0.137 & $\neq$ & & & \\
\hline Depression Malleability & 0.98 & $0.95-1.00$ & 0.084 & $\neq$ & & & \\
\hline Condition ${ }^{\mathrm{a}}$ Depression Malleability & 1.03 & $0.99-1.07$ & 0.150 & $\neq$ & & & \\
\hline Depression identification & 0.96 & $0.94-0.99$ & 0.003 & $\neq$ & 0.97 & $0.95-0.99$ & 0.018 \\
\hline Condition $^{\mathrm{a}}$ Depression identification & 1.04 & $0.99-1.10$ & 0.089 & $\neq$ & & & \\
\hline \multicolumn{8}{|l|}{ REASON ${ }^{d}$} \\
\hline Comfort and competence with mental health care & 0.52 & $0.27-1.03$ & 0.060 & $\neq$ & & & \\
\hline Condition ${ }^{\mathrm{a} C o m f o r t}$ and competence with mental health care & 2.52 & $0.90-7.07$ & 0.079 & $\neq$ & & & \\
\hline Concerns about difficulties with the health care system & 1.26 & $0.85-1.88$ & 0.253 & $\neq$ & & & \\
\hline Condition ${ }^{\mathrm{a} C o n c e r n s}$ about difficulties with the health care system & 0.67 & $0.38-1.18$ & 0.170 & $\neq$ & & & \\
\hline Functional status ${ }^{\mathrm{e}}$ & 1.00 & $0.98-1.02$ & 0.662 & $\neq$ & & & \\
\hline Condition ${ }^{\mathrm{a}}$ Functional status & 1.03 & $1.00-1.05$ & 0.055 & $\neq$ & & & \\
\hline
\end{tabular}

Reference category: No recognition; $\mathrm{OR}=$ odds ratio; $95 \% \mathrm{Cl}=95 \%$ confidence interval; $\mathrm{P}=\mathrm{p}$-value, $\neq$ variables entered in the multivariate model anteraction term

$\mathrm{b}_{4 D S Q}$ Four-Dimensional Symptom Questionnaire

'DAQ Depression Attitude Questionnaire

dREASON questionnaire: GPs' attitudes to their role in the management of anxiety and depressive disorders

eFunctional status was measured with the WHODAS-II World Health Organisation's Disability Assessment Scale II

age, the presence of a chronic medical condition, the 4DSQ scores for somatisation, anxiety and depression, and patients' functional status were not associated with the recognition of anxiety and depression. In addition the DAQ subscales treatment attitude, professional unease and depression malleability were not associated with recognition. As well as the REASON subscales professional comfort with and competence in care of mental health disorders and GPs' concerns about problems with the health care system for management of anxiety and depression. 


\section{Discussion}

\section{Main findings}

The results of this study indicate that patients with a perceived need for psychological care and those with high distress were more likely to be recognized by their GP as having anxiety or depression. This may not come as a big surprise. After all, it is very likely that patients who felt a need for care were more willing to disclose their mental health problems and express their need for care in the doctor's office, thereby obviously increasing the likelihood of subsequent recognition. Similarly, high distress is experienced as "having a difficult time" and this is probably close to having a need for support, advice or guidance. What is more surprising, is that high depression and anxiety were not associated with recognition after accounting for distress. It seems that the severity of psychological suffering (i.e. distress) is associated with recognition, rather than the severity of anxiety and depression. No association was found between somatization and recognition. The presentation of somatic complaints unexplained by physical illness (i.e. somatization) may hinder recognition of anxiety and depression, but this was not confirmed in our study. On the GP part, we found that GPs with confidence in their ability to identify depression were more inclined to recognize patients having anxiety or depression. Besides, GPs who had received the tailored intervention were relatively less likely to recognize anxiety and depression in patients who were married or living together. Possibly, GPs in the intervention group were more focused on the recognition of anxiety and depression particularly in high-risk groups, including people having little or no social support.

In our study the amount of variance in recognition explained by the joint factors in the final model was "poor" to "fair". Recognition seems to be largely determined by other factors, which we can only speculate about. On the part of the GP, we can think of experience with mental health problems, perceived professional responsibilities, sensitivity to emotions, and workload. On the patient part, we might think of past mental health problems, experience with mental health issues in relatives or friends, openness to own emotions, and stigma. On the part of the context of the doctor-patient encounter, we can think of the duration and quality of the doctor-patient relationship, the time available for a consultation (time pressure), and giving priority to one complaint after presentation of various complaints in one consultation.

\section{Comparison with existing literature}

Previous studies have identified patient and GP characteristics that are associated with the recognition or diagnosis of anxiety and depression. However, results are difficult to compare because different definitions of recognition were used, as well as different instruments for the assessment of anxiety and depression.

In our study high 4DSQ distress scores were associated with the recognition of anxiety and depression. Previous research showed that the 4DSQ distress scale turned out to be effective in detecting any depressive or anxiety disorder [54]. Remarkably, high 4DSQ scores on the subscales anxiety and depression were not associated with recognition. The finding is in line with the study of Marcus et al. (2011) [27]. Patients in this study completed four symptom severity self-report questionnaires (i.e. Penn State Worry Questionnaire, Beck Depression Inventory II, Anxiety Sensitivity Index and Mini Social Phobia Inventory) and no association was found with the detection of anxiety and depression. In contrast, other studies showed that patients with more anxiety or depressive symptoms were more likely to be recognized or diagnosed [7, 14, 24-26, 29, 55]. Although instruments used in these studies were different from our study (respectively the Beck Anxiety Inventory, the Depression Screening questionnaire, General Health Questionnaire, Center for Epidemiological Studies Depression Scale, the Composite International Diagnostic Interview and the Patient Health Questionnaire 9), research showed that correlations between the 4DSQ scales and other symptom questionnaires were positive [42]. Furthermore, in keeping with the study of Piek et al. (2012), we found no association between the presence of chronic medical illness and recognition of anxiety and depression [7]. Coventry et al. (2011) found that in the presence of chronic physical health problems GPs and patients tend to normalise distress and depression. As a consequence, depression is less frequently recognized. In addition, Hermanns et al. (2013) concluded in a review that diagnosis and treatment of depression in people with chronic illness (i.e. diabetes) can be improved [56]. An estimated $50 \%$ of patients remain undiagnosed. Other studies, on the other hand, demonstrated a positive association between physical illnesses and recognition [25, 27]. Possibly, in these studies patients with chronic somatic diseases visited their GP more frequently and, as a consequence, were more likely to be recognized. Furthermore, in line with other studies, no association was found between age and recognition [7, 26, 27]. In contrast, a few studies found that patients of higher age were more likely to be recognized [14, 24]. An explanation for this finding might be that anxiety disorders are most common in people aged between 25 and 44 years [57]. In the study of Wittchen et al. (2001) most patients were older [24]. Finally, the finding that patients' need for care was a significant predictor of recognition was confirmed in previous research [27]. 
With respect to the GP characteristics, GPs' attitudes towards anxiety and depression and their ability to detect these disorders were rarely studied. One study examined the associations between attitudes, measured with the DAQ, and clinical behaviour, including depression identification [30]. When comparing both study populations, GPs score on the DAQ components 1, 2 and 4 are similar in our study. GPs score on component 3 'depression malleability' differs significantly between both studies (GPs score in our study was 40.1 and in the study of Dowrick 24.5). In the study of Dowrick et al. (2000) GP visitors completed the General Health Questionnaire 12 (GHQ-12) before the consultation and the GP rated each patient on the severity of their psychological disturbance ranging from 'no disorder' to 'severe disorder' after the consultation. Dorwick et al. (2000) found no association between GPs' confidence in their identification of depression and the accuracy in identifying it among their patients [30]. In contrast, our study showed that GPs having confidence in the ability to identify depression were more likely to recognize patients with anxiety or depression. Possibly, Dorwick et al. (2000) found no association because they used a less specific measurement instrument for the identification of depression, the GHQ-12 which measures general distress [30]. In our study we determined recognition in patient medical records and with several indicators.

\section{Strengths and limitations}

A strength of this study was that we identified recognition using multiple indicators in the medical records. Using diagnostic codes alone may underestimate the accuracy of GPs' recognition of anxiety and depression $[14,43]$. In addition, data on recognition was gathered longitudinally, 6 months before and 6 months after patients completed the EK-10 and were included. Compared to cross-sectional methods, record extraction over an extended period may improve the accuracy of recognition $[12,13]$. For example, because patients may express their psychological complaints in repeated consultations. However, there are inherent methodological limitations when using medical records: complexities in the definition of recognition, recording, assessment and in the exercise of clinical judgement in negotiating diagnoses. Another limitation was that a self-report questionnaire, the EK-10, was used as reference standard for including the participants in this study. Although the EK-10 is an instrument for screening for anxiety and depressive disorders in general practice, a more reliable instrument as reference standard for diagnosis would have been the Composite International Diagnostic Interview (CIDI) [58]. On the other hand, using the EK-10 can also be considered to constitute a strength of the study, providing a wide definition of anxiety and depression in keeping with the relatively non-specific, heterogeneous nature of mental health conditions in general practice.

Creating a regression model using a stepwise procedure to select independent variable in the final model, carries the risk of capitalizing on chance, i.e. the risk of inclusion of variables that coincidentally show significant associations with the outcome in a particular sample. The role of marital status in the recognition of anxiety and depression may have been a chance finding.

By design, by including only positively screened patients, our study did not provide any information on false-positive recognitions.

\section{Practical implications and further research}

Recognition of anxiety and depression is important because of its association with appropriate treatment according to guidelines [59]. Recognition could improve when GPs have more insight in factors associated with the recognition of anxiety and depression. Quality improvement activities may focus at increasing the confidence of GPs in their ability to identify symptoms of distress, anxiety and depression. Smolders et al. (2010) showed that GPs with strong confidence in their abilities to identify depression, treated their patients more often in accordance with guidelines than GPs who had difficulties with distinguishing depression from unhappiness [60]. The use of an instrument, such as the 4DSQ may be helpful to structure the dialogue with the patient, for a better understanding of the complaints and for coming to a shared understanding of the patient's problem [39]. In the presence of chronic physical health problems, GPs and patients have a tendency to normalise distress [18] and may prioritise physical problems [19]. Using the 4DSQ may prevent normalisation of distress. The instrument is helpful in informing the patient and GP about the distress level. A high score $(\geq 21)$ indicates a serious problem, such as a clinically significant psychiatric disorder. Hermanns et al. (2013) concluded that "self-assessment questionnaires can dramatically improve depression detection rates. Complementing such screening with assessments of psychological distress can have an additional and complementary impact on individual self-care" [56]. When using an instrument for recognition, it is important that the instrument fits the holistic focus of patient-centred consultation models favoured by GPs [61]. Certainly, recognition alone is not effective, it has to be part of care including accurate diagnosis, follow-up, and access to evidence-based treatments [62, 63]. Patients have to be informed about their anxiety and depression, about evidence-based treatment options (including watchful waiting) and patients have to express their preferences. In case of major depressive disorders patients have to be 
convinced to initiate and continue treatment [63]. Furthermore, because patients with a perceived need for psychological care were more likely to be recognized, patients should be encouraged in disclosing their problems. Further research is needed into which strategies (individual- and societal level) are effective to disclose mental health problems.

In our study the focus was on factors contributing to the recognition of anxiety and depression in general practice, a small part of quality improvement in primary care. For sustainable improvements in primary mental health care integration with community engagement may contribute to a better recognition of anxiety and depression by the GP [64].

\section{Conclusion}

Patients with a perceived need for psychological care and those with high distress were more likely to be recognized by their GP as having anxiety or depression. In addition, GPs with confidence in their ability to identify depression were more likely to recognize patients with anxiety or depression. Educational efforts should concentrate on increasing GPs' confidence in the ability to identify symptoms of distress, anxiety and depression, as part of care according to guidelines. In addition, patients should be encouraged to disclose their mental health problems.

\section{Additional files}

Additional file 1: Percentages of patients recognised as having

depression or anxiety per potential predictor. (DOCX $37 \mathrm{~kb}$ )

\section{Abbreviations \\ 4DSQ: Four-Dimensional Symptom Questionnaire; AUC: area under the curve; CBS: Central Bureau of Statistics; CIDI: Composite International Diagnostic Interview; DAQ: Depression Attitude Questionnaire; EK-10: extended Kessler 10; GHQ-12: General Health Questionnaire 12; GPs: general practitioners; ICPC-1: International Classification of Primary Care-1; ROC: receiver operating characteristic; SPSS: Statistical Package for the Social Sciences; WHODAS II: World Health Organisation's Disability Assessment Scale II}

\section{Acknowledgements}

We thank the patients and general practitioners for their contribution to this study.

This study was funded by ZonMW, Organisation for Health Research and Development, the Netherlands.

\section{Funding}

This research project was funded by the Netherlands Organisation for Health Research and Development (ZonMW). The funder had no role in the study design, data collection and analysis, interpretation of data or in writing the manuscript.

\section{Availability of data and materials}

The dataset supporting the conclusions of this article is available in consultation with the corresponding author at hsinnema@trimbos.nl

\section{Authors' contributions}

HS contributed to the design of the study, performed the analysis and wrote this article. BT contributed to the design of the study, performed the analysis and co-authored this article. DV contributed to the design of the study and co-authored the article. MW contributed to the design of the study and co-authored the article. AVB contributed to the design of the study and co-authored the article. All authors have read and approved the final manuscript.

Ethics approval and consent to participate

This is a secondary analysis and consent and approval was previously obtained from the Medical Ethics Committee of the Institutions for Mental Health (METiGG; Utrecht, The Netherlands, number NL28350.097.09), and participants gave informed consent.

\section{Competing interests}

H Sinnema: None declared.

B Terluin: is the copyright owner of the $4 D S Q$ and receives copyright fees from companies that use the $4 \mathrm{DSQ}$ on a commercial basis (the $4 \mathrm{DSQ}$ is freely available for non-commercial use in health care and research). BT received fees from various institutions for workshops on the application of the 4DSQ in primary care settings.

D Volker: None declared.

M Wensing: None declared.

A van Balkom: None declared.

\section{Publisher's Note}

Springer Nature remains neutral with regard to jurisdictional claims in published maps and institutional affiliations.

\section{Author details}

${ }^{1}$ Netherlands Institute of Mental Health and Addiction, Trimbos Institute, Postbox 725, 3500, AS, Utrecht, The Netherlands. ${ }^{2}$ Department of General Practice and Elderly Care Medicine, Amsterdam Public Health Research Institute, VU University Medical Centre, Van der Boechorststraat 7, 1081, BT, Amsterdam, The Netherlands. ${ }^{3}$ Universitatsklinikum Heidelberg, Im Neuenheimer Feld 130.3, 69120 Heidelberg, Germany. ${ }^{4}$ Department of Psychiatry, VU University Medical Centre and GGZinGeest, AJ Ernststraat 887, 1081, HL, Amsterdam, The Netherlands.

Received: 20 August 2016 Accepted: 31 May 2018

Published online: 23 June 2018

\section{References}

1. Demyttenaere K, Bruffaerts R, Posada-Villa J, Gasquet I, Kovess V, Lepine JP, et al. Prevalence, severity, and unmet need for treatment of mental disorders in the World Health Organization world mental health surveys. JAMA. 2004;291:2581-90.

2. Alonso J, Angermeyer MC, Bernert S, Bruffaerts R, Brugha TS, Bryson $\mathrm{H}$, et al. Disability and quality of life impact of mental disorders in Europe: results from the European study of the epidemiology of mental disorders (ESEMeD) project. Acta Psychiatr Scand Suppl. 2004;420:38-46.

3. Gustavsson A, Svensson M, Jacobi F, Allgulander C, Alonso J, Beghi E, et al. Cost of disorders of the brain in Europe 2010. Eur Neuropsychopharmacol. 2011:21:718-79.

4. van Avendonk $\mathrm{M}$, van Weel-Baumgarten $\mathrm{E}$, van der Weele $\mathrm{G}$, Wiersma $\mathrm{T}$, Burgers JS. Summary of the Dutch College of General Practitioners' practice guideline 'Depression'. Ned Tijdschr Geneeskd. 2012;156:A5101.

5. van Avendonk MJ, Hassink-Franke LJ, Terluin B, van Marwijk HW, Wiersma T, Burgers JS: [Summarisation of the NHG practice guideline 'Anxiety']. Ned Tijdschr Geneeskd 2012, 156: A4509.

6. Lecrubier Y. Widespread underrecognition and undertreatment of anxiety and mood disorders: results from 3 European studies. J Clin Psychiatry. 2007;68:36-41.

7. Piek E, Nolen WA, van der Meer K, Joling KJ, Kollen BJ, Penninx BW, et al. Determinants of (non-)recognition of depression by general practitioners: results of the Netherlands study of depression and anxiety. J Affect Disord. 2012;138:397-404

8. Andrews G, Issakidis C, Sanderson K, Corry J, Lapsley H. Utilising survey data to inform public policy: comparison of the cost-effectiveness of treatment of ten mental disorders. Br J Psychiatry. 2004;184:526-33.

9. Gijsen R, Poos M: Zorggebruik:nadere uitwerking. In: Volksgezondheid Toekomstverkenning, Nationaal Kompas Volksgezondheid. Bilthoven: RIVM; 2012. 
10. Verhaak PF, van Dijk CE, Nuijen J, Verheij RA, Schellevis FG. Mental health care as delivered by Dutch general practitioners between 2004 and 2008. Scand J Prim Health Care. 2012;30:156-62.

11. Cepoiu M, McCusker J, Cole MG, Sewitch M, Belzile E, Ciampi A. Recognition of depression by non-psychiatric physicians-a systematic literature review and meta-analysis. J Gen Intern Med. 2008;23:25-36.

12. Mitchell AJ, Vaze A, Rao S. Clinical diagnosis of depression in primary care: a meta-analysis. Lancet. 2009;374:609-19.

13. Kessler D, Bennewith $\mathrm{O}$, Lewis $\mathrm{G}$, Sharp D. Detection of depression and anxiety in primary care: follow up study. BMJ. 2002;325:1016-7.

14. Janssen EH, van de Ven PM, Terluin B, Verhaak PF, van Marwijk HW, Smolders $\mathrm{M}$, et al. Recognition of anxiety disorders by family physicians after rigorous medical record case extraction: results of the Netherlands Study of Depression and Anxiety. Gen Hosp Psychiatry. 2012:34:460-7.

15. Verhaak $P$, Prins MA, Spreeuwenberg P, Draisma S, van Balkom T, Bensing $J M$, et al. Receiving treatment for common mental disorders. Gen Hosp Psychiatry. 2009;31:46-55.

16. Wittkampf KA, van ZM, Smits FT, Schene AH, Huyser J, van Weert HC. Patients' view on screening for depression in general practice. Fam Pract. 2008;25:438-44.

17. Tylee A, Walters P. Underrecognition of anxiety and mood disorders in primary care: why does the problem exist and what can be done? I Clin Psychiatry. 2007;68(Suppl 2):27-30.

18. Chew-Graham C, Kovandzic M, Gask L, Burroughs H, Clarke P, Sanderson H, et al. Why may older people with depression not present to primary care? Messages from secondary analysis of qualitative data. Health Soc Care Community. 2012;20:52-60.

19. Overend K, Bosanquet K, Bailey D, Foster D, Gascoyne S, Lewis H, et al. Revealing hidden depression in older people: a qualitative study within a randomised controlled trial. BMC Fam Pract. 2015;16:142.

20. Prins MA, Verhaak PF, Smolders M, Laurant MG, van der Meer $K$, Spreeuwenberg $P$, et al. Patient factors associated with guidelineconcordant treatment of anxiety and depression in primary care. J Gen Intern Med. 2010;25:648-55.

21. Barley EA, Murray J, Walters P, Tylee A. Managing depression in primary care: a meta-synthesis of qualitative and quantitative research from the UK to identify barriers and facilitators. BMC Fam Pract. 2011;12:47.

22. Coventry PA, Hays R, Dickens C, Bundy C, Garrett C, Cherrington A, et al. Talking about depression: a qualitative study of barriers to managing depression in people with long term conditions in primary care. BMC Fam Pract. 2011;12:10

23. Kovandzic M, Chew-Graham C, Reeve J, Edwards S, Peters S, Edge D, et al. Access to primary mental health care for hard-to-reach groups: from 'silent suffering' to 'making it work. Soc Sci Med. 2011;72:763-72.

24. Wittchen HU, Hofler M, Meister W. Prevalence and recognition of depressive syndromes in German primary care settings: poorly recognized and treated? Int Clin Psychopharmacol. 2001;16:121-35

25. Nuyen J, Volkers AC, Verhaak PF, Schellevis FG, Groenewegen PP, Van den Bos GA. Accuracy of diagnosing depression in primary care: the impact of chronic somatic and psychiatric co-morbidity. Psychol Med. 2005;35:1185-95.

26. Pfaff JJ, Almeida OP. A cross-sectional analysis of factors that influence the detection of depression in older primary care patients. Aust N Z J Psychiatry. 2005:39:262-5.

27. Marcus M, Westra H, Vermani M, Katzman M. Patient predictors of detection of depression and anxiety disorders in primary care. Journal of Participatory Medicine. 2011;

28. Rifel J, Svab I, Ster MP, Pavlic DR, King M, Nazareth I. Impact of demographic factors on recognition of persons with depression and anxiety in primary care in Slovenia. BMC Psychiatry. 2008;8:96.

29. Chin WY, Chan KT, Lam CL, Wong SY, Fong DY, Lo YY, et al. Detection and management of depression in adult primary care patients in Hong Kong: a cross-sectional survey conducted by a primary care practice-based research network. BMC Fam Pract. 2014;15:30.

30. Dowrick C, Gask L, Perry R, Dixon C, Usherwood T. Do general practitioners' attitudes towards depression predict their clinical behaviour? Psychol Med. 2000;30:413-9.

31. Ross S, Moffat K, McConnachie A, Gordon J, Wilson P. Sex and attitude: a randomized vignette study of the management of depression by general practitioners. Br J Gen Pract. 1999;49:17-21.
32. Robbins JM, Kirmayer $L$, Cathebras P, Yaffe MJ, Dworkind M. Physician characteristics and the recognition of depression and anxiety in primary care. Med Care. 1994;32:795-812.

33. Sinnema H, Franx G, Volker D, Majo C, Terluin B, Wensing M, et al. Randomised controlled trial of tailored interventions to improve the management of anxiety and depressive disorders in primary care. Implement Sci. 2011;6:75

34. Terluin B, van Heest F, van der Meer K, Neomagus G, Hekman J, Aulbers L et al:: Dutch College of General Practitioners guideline: anxiety disorder, first revision [NHG-Standaard Angststoornissen, eerste herziening. In Dutch]. Huisarts en Wetenschap 2004, 47: 26-37.

35. Richtlijnwerkgroep Multidisciplinaire richtlijnen Angststoornissen en Depressie: Multidisciplinary guideline Anxiety Disord: guideline for diagnostics and treatment of adult clients with an anxiety disorder, first revision [Multidisciplinaire richtlijn Angststoornissen. Richtlijn voor de diagnostiek en behandeling van volwassen patiënten met een angststoornis, eerste revisie. In Dutch]. Utrecht:Trimbos-instituut; 2009

36. Van Marwijk HWJ, Grundmeijer HGLM, Bijl D, Van Gelderen MG, De Haan M, Van Weel-Baumgarten EM. Dutch College of General Practitioners guideline: depression, first revision [NHG-Standaard Depressieve stoornis (depressie). Eerste herziening. In Dutch]. Huisarts \& Wetenschap. 2003;46:614-23.

37. Richtlijnwerkgroep Multidisciplinaire richtlijnen Angststoornissen en Depressie: Multidisciplinary guideline depression: guideline for diagnostics and treatment of adult clients with a major depressive disorder, first revision [Multidisciplinaire richtlijn Depressie: richtlijn voor diagnostiek en behandeling van volwassen cliënten met een depressie, eerste revisie. In Dutch]. Utrecht: Trimbos-instituut; 2009.

38. Sinnema H, Majo MC, Volker D, Hoogendoorn A, Terluin B, Wensing M, et al Effectiveness of a tailored implementation programme to improve recognition, diagnosis and treatment of anxiety and depression in general practice: a cluster randomised controlled trial. Implement Sci. 2015;10:33.

39. Sinnema $H$, Terluin $B$, Wensing $M$, Volker $D$, Franx $G$, van BA, et al. Systematic tailoring for the implementation of guideline recommendations for anxiety and depressive disorders in general practice: perceived usefulness of tailored interventions. BMC Fam Pract. 2013:14:94.

40. Donker T, Comijs H, Cuijpers P, Terluin B, Nolen W, Zitman F, et al. The validity of the Dutch $\mathrm{K} 10$ and extended K10 screening scales for depressive and anxiety disorders. Psychiatry Res. 2010;176:45-50.

41. Lamberts HWM. International classification of primary care (ICPC). Oxford: Oxford University Press; 1990.

42. Terluin B, van Marwijk HW, Ader HJ, de Vet HC, Penninx BW, Hermens $\mathrm{ML}$, et al. The four-dimensional symptom questionnaire (4DSQ): a validation study of a multidimensional self-report questionnaire to assess distress, depression, anxiety and somatization. BMC Psychiatry. 2006;6:34

43. Joling KJ, van Marwijk HW, Piek E, van der Horst HE, Penninx BW, Verhaak $\mathrm{P}$, et al. Do GPS' medical records demonstrate a good recognition of depression? A new perspective on case extraction. J Affect Disord. 2011:133:522-7.

44. Hakkaart-van Roijen L: Manual Trimbos/iMTA questionnaire for costs associated with psychiatric illness [in Dutch]. Rotterdam: Institute for Medical Technology Assessment; 2002.

45. Chwastiak LA, Von Korff M. Disability in depression and back pain evaluation of the World Health Organization disability assessment schedule (WHO DAS II) in a primary care setting. J Clin Epidemiol. 2003;56:507-14.

46. Ustun TB, Chatterji S, Kostanjsek N, Rehm J, Kennedy C, Epping-Jordan J, et al. Developing the World Health Organization disability assessment schedule 2.0. Bull World Health Organ. 2010;88:815-23.

47. Botega N, Blizard R, Wilkinson G. General practitioners and depression-first use of the depression attitude questionnaire. Int J Methods Psychiatr Res. 1992;4:169-80.

48. Haddad M, Menchetti M, Walters P, Norton J, Tylee A, Mann A. Clinicians' attitudes to depression in Europe: a pooled analysis of depression attitude questionnaire findings. Fam Pract. 2012;29:121-30.

49. McCall L, Clarke DM, Rowley G. A questionnaire to measure general practitioners' attitudes to their role in the management of patients with depression and anxiety. Aust Fam Physician. 2002;31:299-303.

50. Twisk JWR. Applied multilevel analysis. Cambridge: Cambridge University Press; 2006

51. Rubin DB. Multiple imputation for nonresponse in surveys. New York: John Wiley \& Sons; 1987. 
52. Harrell FE Jr, Lee KL, Matchar DB, Reichert TA. Regression models for prognostic prediction: advantages, problems, and suggested solutions, Cancer Treat Rep. 1985;69:1071-7.

53. Tape T: Interpreting Diagnostics Tests. Omaha: University of Nebraska Medical Centre; 2004.

54. Terluin B, Brouwers EP, van Marwijk HW, Verhaak P, van der Horst HE. Detecting depressive and anxiety disorders in distressed patients in primary care; comparative diagnostic accuracy of the four-dimensional symptom questionnaire (4DSQ) and the hospital anxiety and depression scale (HADS). BMC Fam Pract. 2009;10:58.

55. Kamphuis MH, Stegenga BT, Zuithoff NP, King M, Nazareth I, de Wit NJ, et al. Does recognition of depression in primary care affect outcome? The PREDICT-NL study. Fam Pract. 2012;29:16-23.

56. Hermanns N, Caputo S, Dzida G, Khunti K, Meneghini LF, Snoek F. Screening, evaluation and management of depression in people with diabetes in primary care. Prim Care Diabetes. 2013;7:1-10.

57. Flint AJ. Epidemiology and comorbidity of anxiety disorders in the elderly. Am J Psychiatry. 1994;151:640-9.

58. Wittchen HU. Reliability and validity studies of the WHO-composite international diagnostic interview (CIDI): a critical review. J Psychiatr Res. 1994;28:57-84.

59. Smolders M, Laurant M, Verhaak P, Prins M, van Marwijk H, Penninx B, et al. Adherence to evidence-based guidelines for depression and anxiety disorders is associated with recording of the diagnosis. Gen Hosp Psychiatry. 2009;31:460-9.

60. Smolders M, Laurant M, Verhaak P, Prins M, van Marwijk H, Penninx B, et al. Which physician and practice characteristics are associated with adherence to evidence-based guidelines for depressive and anxiety disorders? Med Care. 2010;48:240-8.

61. Mitchell C, Dwyer R, Hagan T, Mathers N. Impact of the QOF and the NICE guideline in the diagnosis and management of depression: a qualitative study. Br J Gen Pract. 2011;61:e279-89.

62. Gilbody S, Sheldon T, Wessely S. Should we screen for depression? BMJ. 2006;332:1027-30

63. Baas KD, Wittkampf KA, van Weert HC, Lucassen P, Huyser J, van den Hoogen $\mathrm{H}$, et al. Screening for depression in high-risk groups: prospective cohort study in general practice. Br J Psychiatry. 2009;194:399-403.

64. Dowrick C, Bower P, Chew-Graham C, Lovell K, Edwards S, Lamb J, et al. Evaluating a complex model designed to increase access to high quality primary mental health care for under-served groups: a multi-method study. BMC Health Serv Res. 2016;16:58.

Ready to submit your research? Choose BMC and benefit from:

- fast, convenient online submission

- thorough peer review by experienced researchers in your field

- rapid publication on acceptance

- support for research data, including large and complex data types

- gold Open Access which fosters wider collaboration and increased citations

- maximum visibility for your research: over $100 \mathrm{M}$ website views per year

At BMC, research is always in progress.

Learn more biomedcentral.com/submissions 